\title{
Healable polymeric materials: a tutorial review
}

Article

Accepted Version

Burattini, S., Greenland, B. W., Chappell, D., Colquhoun, H. M. and Hayes, W. (2010) Healable polymeric materials: a tutorial review. Chemical Society Reviews, 39 (6). pp. 1973-1985. ISSN 0306-0012 doi: https://doi.org/10.1039/b904502n Available at https://centaur.reading.ac.uk/16424/

It is advisable to refer to the publisher's version if you intend to cite from the work. See Guidance on citing.

Published version at: http://pubs.rsc.org/en/Content/ArticleLanding/2010/CS/b904502n

To link to this article DOI: http://dx.doi.org/10.1039/b904502n

Publisher: RSC Publishing

All outputs in CentAUR are protected by Intellectual Property Rights law, including copyright law. Copyright and IPR is retained by the creators or other copyright holders. Terms and conditions for use of this material are defined in the End User Agreement.

\section{www.reading.ac.uk/centaur}

\section{CentAUR}

Central Archive at the University of Reading

Reading's research outputs online 


\title{
Healable polymeric materials: A tutorial review
}

S. Burattini, B. W. Greenland, D. Chappell, H. M. Colquhoun* and W. Hayes*

Department of Chemistry, University of Reading, Whiteknights, Reading, RG6 6AD. Email: w.c.hayes@reading.ac.uk, h.m.colquhoun@reading.ac.uk

\begin{abstract}
Given the extensive use of polymers in the modern age with applications ranging from aerospace components to microcircuitry, the ability to regain the mechanical and physical characteristics of complex pristine materials after damage is an attractive proposition. This tutorial review focusses upon the key chemical concepts that have been successfully utilised in the design of healable polymeric materials.
\end{abstract}

\section{Introduction}

Polymeric materials underpin almost every aspect of everyday life with, for example, electronic, ${ }^{1,2}$ automotive, ${ }^{2,3,4}$ coating, ${ }^{5}$ and sports technologies ${ }^{2,6,7}$ employing a very wide range of organic macromolecules. However, continuous exposure of these polymers to environmental stresses including chemical attack, radiation damage, mechanical abrasion, impact and thermal decomposition alone or in combination ${ }^{8}$ - can result in degradation of the material's physical properties and lead to irreversible damage. It has been proposed ${ }^{9}$ that this process starts at the microscopic level with the formation of microvoids, which then expand to generate microcracks (difficult to detect) ${ }^{10}$ and ultimately lead to formation of macroscopic cracks. The resulting loss of structural integrity leads to diminution of mechanical performance and ultimately to failure of the polymeric component.

Conventional repair methods such as welding or patching can sometimes be applied at the macroscopic level to either rejoin or reinforce damaged areas. However, these solutions are not always viable either as a result of inaccessibility to the damaged area or because they lead to changes in the dimensions and surface finish of the material. ${ }^{11}$ Moreover, polymers which are conventionally crosslinked or which (when linear) have molecular weights exceeding the 
entanglement limit, must necessarily fracture by breaking covalent bonds. Restoration of the physico-mechanical properties of such materials, once fractured, requires either new covalent chemistry to generate additional crosslinks, or long periods of annealing to enable thermal diffusion of unbroken, linear polymer chains into the damage-zone.

In view of the extensive use of polymers and polymer-composites in modern technologies, much recent research has focused on the creation of organic materials that are able to heal and repair themselves, either autonomically or in response to some form of stimulus such as heat or light. ${ }^{11,12,13}$ In this context, a "healable" polymer may be defined as one that can, after fracture, regain fully the mechanical strength of the pristine material.

The present tutorial review aims to introduce the reader to research in this field, outlining the key concepts and mechanisms underpinning the design and processing of healable polymeric materials, and indicating potential directions for progress in the future development of these fascinating and potentially valuable materials.

\section{General considerations}

The primary goal in designing a healable material is to produce a macromolecular system which is able to rapidly and completely regain its physical properties during the repair process. In practice, this may not always be possible, the "healed" material having reduced tensile strength or elasticity when compared to an undamaged sample. The recovery in performance relative to the pristine material is then defined in terms of a "healing efficiency". This simple, dimensionless parameter is the ratio of a specific mechanical property (e.g. tensile modulus or extension to break) of the material, measured before and after healing, and expressed as a percentage (Equation 1). ${ }^{11,12}$

Equation 1: $\quad$ Healing Efficiency $=\frac{\text { Mechanical value }_{\text {healed }}}{\text { Mechanical value }_{\text {pristine }}} \times 100$ 
Whilst healing efficiency is a very useful measure of the success of the healing process, it must be treated with caution if only a single parameter of this type is cited in isolation, as it does not indicate whether other properties of the healed material have been recovered to the same extent. In addition there is, as yet, no standard definition of what actually constitutes a fractured material, so that healing efficiencies may be for example be calculated either after healing of a single microscopic crack or (in a very different process) after a material has been broken and the parts then separated and rejoined prior to the healing efficiency measurement.

Further considerations which may affect the applicability of healable materials in a specific application include (a) the healing rate, (b) whether the polymer can be repeatedly healed at the same fracture-point and (c) the extent to which the material regains its original properties at the damage-site, whether these be tensile strength, storage modulus, elasticity, colour or optical clarity.

\section{Strategies used to afford healable materials}

Healable polymeric materials fall into two broad classes, differentiated by whether an external stimulus is needed to promote the healing process. Autonomically healable materials, once fractured, regain the physical properties of the pristine material without such external intervention. In contrast, rehealable or remendable materials regain their original physical properties in response to a specific external stimulus. In either case, regardless of whether intervention is necessary, a healable polymer must possess the ability to form multiple new bonding interactions in and around the damage-zone by harnessing components from within its existing structure. To date, this challenge has been addressed by four distinctly different strategies: (a) the encapsulated-monomer approach, (b) reversible covalent bond formation, (c) irreversible covalent bond formation and (d) supramolecular self-assembly.

\subsection{Encapsulated monomer approach}

The encapsulated-monomer approach has been developed mainly for crosslinked materials, typically epoxy resins. The healable versions of such materials contain 
reservoirs of a monomer (the healing agent) and a polymerisation initiator or catalyst, which are spatially separated within the bulk of the material. Healing is triggered by the fracture itself, as this facilitates mixing of the monomer and initiator (or catalyst) by capillary action, and thus leads to formation of new polymeric material within the fracture-voids. In the majority of cases so far reported, the healed zone is chemically distinct from the composition of the bulk material. $^{12}$ The first attempt to incorporate self-healing properties into a polymer system of this type was reported by White and co-workers in 2001 . The material comprised an epoxy resin, impregnated with Grubbs' catalyst 1 and containing dispersed microcapsules of monomeric dicyclopentadiene 2 (Scheme 1 and Figure 1). ${ }^{14}$

\section{$<$ Scheme 1 here $>$}

In this system the healing process is initiated when a propagating crack ruptures a microcapsule, releasing the healing agent. The healing agent is drawn by capillary action into the crack where ring-opening metathesis polymerization, mediated by the embedded catalyst $\mathbf{1}$, produces a new crosslinked polymer $\mathbf{3}$ within the void originally created by the fracture (Figure 1).

\section{$<$ Figure 1 here>}

The heterogeneous nature of this material also provides an additional advantage over its ability to heal the fracture, as microcrack propagation is hindered when dispersed catalyst particles or microcapsules are encountered by the growing crack.

The healing efficiency for this material was however only $75 \%$ in toughness, so that the healed polymer was predisposed to further fracture at the weaker, healed zone, rather than in an undamaged area. A potential drawback of this initial approach is that, should such a repeat-fracture occur, the material is then unable to re-heal because the healing agent has already been consumed during repair of the initial break. Side issues are the cost of the precious-metal-based catalyst and its long-term stability within the epoxy matrix. 
To overcome these shortcomings of catalyst cost and potential instability, White and co-workers devised a second-generation healing material based on the same general principle of spatially-separated healing agents and catalyst. ${ }^{15}$ This system makes use of readily-available and relatively low cost components, including the siloxane-based macromonomers $\mathbf{4}$ and $\mathbf{5}$ which undergo polymerisation in the presence of a tin-based catalyst $\mathbf{6}$. Mechanical damage propagating through the material releases the catalyst from polyurethane microcapsules and leads to rapid polycondensation of the siloxane macromonomers (4 and $\mathbf{5}$ ) to form a siloxane crosslinked network within the damaged zone (7 Scheme 2). The hydrophobic nature of the siloxane-based healing agents enables the material to remain stable in wet and humid environments, but this methodology does not improve the healing efficiency of the system (which is as low as $24 \%$ ) and is still unable to repair the material after more than a single damage-event at a given site.

\section{<Scheme 2 here>}

In order to produce a material that is capable of autonomic repair of repeated fractures at the same site, White's group have developed ${ }^{16}$ a microvascular network that contains refillable hollow channels. This third generation of autonomous healable polymers comprises a layer of epoxy resin containing Grubbs' catalyst 1 deposited onto a three-dimensional microchannelled substrate containing the liquid monomer dicyclopentadiene $\mathbf{2}$, which is itself embedded in a crosslinked epoxy matrix (Figure 2a). When damage occurs, the liquid healing agent is driven into the crack through capillary action, whereupon polymerisation (Scheme 1) occurs through contact with the embedded catalyst. The repeated healability of this material was demonstrated by first inducing cracks in a four-point bending test, and then comparing the maximum load of the resulting healed polymer with the value of the pristine sample. After testing, the network was left for 12 hours at $25{ }^{\circ} \mathrm{C}$ to cure and was then re-filled with the healing agent before the next bending test. A peak recovery (healing efficiency) of $70 \%$ was reported after the second healing cycle, on the basis of the ratio of the critical loads for crack opening in healed and pristine materials (Figure 2b). The material exhibited healing efficiencies of between 30 and $70 \%$ over 7 break/heal/re-fill cycles, 
conclusively demonstrating to advantage delivering the healing agents through refillable channels rather than from discrete microcapsules.

\section{$<$ Figure 2 here $>$}

An alternative healable system, which incorporates hollow, borosilicate glass fibres filled with a curing resin-system in a polymer matrix, has been described by Pang and Bond. ${ }^{17,18} \mathrm{~A}$ proportion of the fibres in this autonomously-repairable system are filled (using a vacuum-assisted infiltration technique) with an epoxy resin repair agent incorporating a UV fluorescent dye, and the remainder are filled with an epoxy-hardener. When a breaking stress is applied to the matrix, the hollow fibres fracture and release the two epoxy-components. Subsequent mixing of resin and hardener allows self-healing to take place, with the progress of the healing

process being visualised through irradiation by UV light (Figure 3, top). The strength of the composite was measured using a four-point bend flexural testing process. By taking a damaged, unhealed sample and a pristine sample as a lower and upper limit reference respectively, the flexural strength improved after healing for both $24 \mathrm{~h}$ at ambient temperature and $1.5 \mathrm{~h}$ at $40{ }^{\circ} \mathrm{C}$ (Figure 3 bottom), although neither sample was as strong as the pristine material.

\section{<Figure 3 here>}

A potential improvement to this approach has been proposed ${ }^{19}$ by Sijbesma and co-workers, who have developed a polymer-functionalised $\mathrm{N}$-heterocyclic carbene which can bind catalytic metal centres such as silver(I) or ruthenium(II) complexes. These latent catalysts can be activated mechanically by application of ultrasound, and then initiate a polymerization reaction such as ring-opening metathesis of cyclooctene. If such a mechanochemically-initiated process could be tailored to be applicable in the solid state, then this mechanism might offer an alternative route to autonomously-healable materials.

\subsection{Reversible covalent bond formation}

In this approach, the bulk polymer contains covalent crosslinks which are designed to undergo well-defined and fully-reversible bond breaking and bond forming 
reactions during healing. As a consequence, the material within the healed zone can be chemically identical to that of the bulk polymer.

Based on the pioneering studies of Steven and Jenkins, who produced a thermally-reversible polymer network employing a Diels-Alder reaction, ${ }^{20}$ Wudl and co-workers have reported the development of a transparent polymeric material 8 which is crosslinked by reactions of diene (furan) $\mathbf{9}$ and dienophile (maleimide) units $10 .^{21}$ This highly crosslinked polymer was formed by the cycloaddition of a tris-maleimide $\mathbf{1 0}$ with a tetra-furan $\mathbf{9}$ (Scheme 3).

\section{$<$ Scheme 3 here $>$}

The thermally reversible nature of Diels-Alder reactions ${ }^{22}$ has been utilized very successfully by Wudl's group in the creation of thermally-healable polymers. They proposed that the predominant mechanism for crack propagation involved the scission of covalent bonds within the Diels-Alder adduct via retro Diels-Alder chemistry. Hence, taking advantage of the thermal reversible properties of the Diels-Alder reaction, reheating the sample to temperatures greater than $120^{\circ} \mathrm{C}$ under an inert atmosphere for 2 hours, followed by cooling to room temperature, enabled reformation of new covalent bonds via [4+2] cycloaddition reactions and consequent healing of the fractured material. This methodology resulted in a material which showed a healing efficiency of $57 \%$ based on load-displacement curves obtained after fracture tests (Figure 4).

\section{$<$ Figure 4 here $>$}

The healing efficiencies of materials developed using this approach were subsequently improved to $87 \%$, by incorporating bis-dienophile $\mathbf{1 1}$ in the system to produce crosslinked polymer 12 (Scheme 4$){ }^{23}$

\section{<Scheme 4 here>}

Crucially, the healing efficiency of the optimised Diels-Alder network remained above $80 \%$ in materials that were repeatedly fractured at the same site. This result highlights the advantages of harnessing constituent molecular subunits within the 
polymer itself (rather than components segregated in microcapsules) to achieve healing through covalent bond formation.

Related healable systems which exploit the reversibility of the Diels-Alder reaction have been reported by Liu and $\mathrm{Hsieh}^{24}$ using tris-maleimide $\mathbf{1 3}$ and tris-furan $\mathbf{1 4}$ to generate the hydroxy-functionalised resin 15 (Scheme 5).

\section{$<$ Scheme 5 here $>$}

The polymer network 15 was produced by depositing the monomers (13 and 14) from acetone solution onto an aluminium plate. After evaporation of the solvent, the monomers were crosslinked at $50^{\circ} \mathrm{C}$ for 12 hours. The healing properties of the resulting film 15 were investigated via microscopic analysis. SEM analysis (Figure 5) revealed that a knife-cut in the surface of the film could be repaired by thermal treatment at $50{ }^{\circ} \mathrm{C}$ for 12 hours or at $120^{\circ} \mathrm{C}$ for 20 minutes, which led to covalent-bond-formation via the expected cycloaddition reaction.

\section{$<$ Figure 5 here $>$}

This approach was subsequently modified to produce linear polymers containing pendant maleimide 16 and furan groups 17. The linear polymers were again thermally crosslinked via Diels-Alder cycloaddition reactions to afford polymer

networks such as 18 (Scheme 6). ${ }^{25,26}$ The versatility of this approach allowed the synthesis of a library of polyamide-based prepolymers each containing pendant maleimide and furan groups.

\section{$<$ Scheme 6 here>}

It was demonstrated that polymer $\mathbf{1 8}$ is a relatively tough material with a Young's modulus of $566 \mathrm{MPa}$, an elongation to break of $4.4 \%$, and a breaking-stress of 20 $\mathrm{MPa}$. However, in contrast to polymer 15, SEM images and rheological analysis of this system revealed that this system, when cut and re-healed at $120{ }^{\circ} \mathrm{C}$ for a period of 3 hours, or at $50{ }^{\circ} \mathrm{C}$ for 5 days showed only limited recovery of mechanical properties. 
In 2009, Broekhuis et al. reported ${ }^{27}$ a polyketone bearing pendant furan groups 19 that could be crosslinked via Diels-Alder cycloaddition with a bis-maleimide 20 to afford a novel recyclable network 21 (Scheme 7).

\section{$<$ Scheme 7 here $>$}

Recycling of polymer $\mathbf{2 1}$ was achieved by grinding the sample, followed by subjecting the powder to compression moulding $\left(120^{\circ} \mathrm{C}, \mathrm{ca} .20\right.$ minutes) to give a new bulk polymer sample. Three-point bending tests illustrated the ability of the network to recover its original microstructure even after multiple healing cycles (Figure 6).

\section{$<$ Figure 6 here>}

Recyclable polymers such as $\mathbf{2 1}$ show a number of desirable intrinsic properties, for example behaving as thermosets at room temperature, with optical transparency and high tensile strength (>100 MPa). They have also been shown to undergo multiple healing cycles at the same damage-site whilst maintaining good healing efficiencies $(\approx 80 \%)$. However, elevated temperatures $\left(>120{ }^{\circ} \mathrm{C}\right)$ are generally required to produce healing through reverse Diels-Alder chemistry, and in several cases high pressure was also needed to achieve optimum healing.

In principle, any reversible covalent bond forming reaction can be employed to produce a healable material. An interesting example has been described by Chung and co-workers, who synthesised a PMMA monolith with cyclobutanediyl crosslinks $22 .^{28}$ Crosslinking was induced by the reversible [2+2] cycloaddition between the cinnamoyl groups of $\mathbf{2 3}$ to produce the photochemically-healable polymer 22 (Scheme 8).

\section{$<$ Scheme 8 here $>$}

It was proposed that external stress can ring-open the highly strained cyclobutanediyl crosslinks (strain energy of $\left.26.4 \mathrm{kcal} \mathrm{mol}^{-1}\right)^{29}$ resulting in the corresponding cinnamoyl precursor 23. Irradiation of the damaged material with UV light $($ ca. $280 \mathrm{~nm})$, promotes the [2+2] cycloaddition reaction to once again 
prepare 22. Analysis of the cracked and healed samples revealed a healing efficiency of $20 \%$ (based on flexural strength) when the material was simultaneously heated at $100^{\circ} \mathrm{C}$ and photo-irradiated for a period of 10 minutes. The presence of the cyclobutanediyl crosslinks was verified by FTIR spectroscopy, which enabled continuous monitoring of the decreasing intensity of the alkene $(v \mathrm{C}=\mathrm{C})$ stretching band at $1637 \mathrm{~cm}^{-1}$.

Reversible photochemical cleavage of allyl sulfide linkages can also be used as an alternative to the reversible Diels-Alder reaction. Although healing properties of materials afforded by this reaction have yet to be reported, Bowman and coworkers have demonstrated ${ }^{30}$ that photoinduced reversible chain rearrangements in a crosslinked elastomer containing allyl sulfide groups (Scheme 9) can release accumulated stress in a strained system, even at room temperature. If this mechanism can be applied to more rigid materials, then the development of low residual-stress networks capable of exhibiting healable characteristics can be envisaged.

\section{$<$ Scheme 9 here $>$}

\subsection{Irreversible Covalent Bond Formation}

In this approach, the bulk material contains functionalities which can react together to form new covalent bonds and thereby bridge a damaged zone. The new crosslinks are as thermodynamically stable as the covalent bonds present in the bulk material from which they originated, and the chemical composition of the healed zone may be distinct from that found in the bulk material (Scheme 10).

\section{$<$ Scheme 10 here $>$}

Urban and co-workers have, for example, developed a photo-healable system 24 based on an oxetane-substituted chitosan precursor 25, incorporated into a twocomponent polyurethane derived from isocyanate $\mathbf{2 6}$ and glycol 27 (Scheme 11). ${ }^{31}$

<Scheme 11 here $>$ 
This approach takes advantage of the UV-sensitivity of the four-membered oxetane ring which is pendant on the chitosan backbone. ${ }^{31}$ When a solid film of this network was mechanically damaged, scission occurred at the urea and ether linkages of the chitosan. It was proposed that repair of the damaged area was facilitated by high frequency radiation $(280-400 \mathrm{~nm})$ which provided sufficient energy to open the strained four-membered oxetane ring and restore the crosslinked network. Self-healing behaviour was observed ${ }^{31}$ via IR spectroscopic analysis and optical microscopy of the mechanically damaged film following UV irradiation (Figure 7).

\section{$<$ Figure 7 here>}

\subsection{Supramolecular self-assembly}

Linear polymers can be thermally re-healed when two broken sections are brought together, as a consequence of the thermal diffusion of polymer chains across the interface. However, healing is only observed when the polymer is held above its glass transition temperature $\left(T_{g}\right)$, for a period of time greater than the reptation time $\left(T_{r}\right) .32,33,34,35$ These results correlate well with the reptation model for polymer chain-diffusion developed by De Gennes, ${ }^{32}$ who proposed that polymer chains within a bulk material diffuse by thermally-induced random motions which are constrained within fixed, tube-like voids. Thus, for a crack in a thermoplastic to heal under thermal control, macromolecules must diffuse across the interface between two sections of broken polymer, before interpenetrating and finally reentangling with neighbouring chains, thereby knitting the two portions of the thermoplastic together (Scheme 12).

\section{<Scheme 12 here>}

Independent healing studies on thermoplastic polymers by Kausch et al. ${ }^{33}$ and Wool et al. ${ }^{34}$ and more recently by Prud'homme et al. ${ }^{35}$ have shown that is possible to re-attain the original strength of the pristine material, but that its fatigue resistance may be dramatically reduced below the maximum value. ${ }^{12}$

A conceptually different approach is to employ a bulk material that features numerous non-covalent bonds which can hold together a network of oligomer or 
polymer chains. In this class of healable material, it is (at least in principle) the non-covalent bonding interactions in the structure which break during fracture and reform upon healing. As a consequence, the composition of the healed zone is theoretically identical to that of the bulk material. The development of supramolecular polymers, ${ }^{36,37,38,39,40,41}$ has thus provided opportunities for designing a supramolecular networks which possess the inherent ability to selfrepair. $^{42}$

The potential for metal-ligand interactions to be used in healable materials has long been recognised, ${ }^{43}$ with work in this area demonstrating the reversibility of metal-ligand interactions at the single-molecule level. ${ }^{44}$ Studies on bulk materials were conducted by Kalista et al. who found that modification of commercially sourced carboxlyate ionomers could produce materials that spontaneously heal after ballistic damage. ${ }^{45,46}$ Furthermore, a recent report by Aida et al. has detailed a hydrogel maintained by electrostatic interactions between the positively charged surface groups of dendritic macromolecules and anionic clay nano-sheets. This hydrogel has been shown to be a self-supporting material that exhibits healable properties. ${ }^{47}$

Leibler has reported a study of the self-healing and thermoreversibility characteristics of a supramolecular elastomer. ${ }^{48}$ Here, a mixture of oligomers containing complementary hydrogen-bonding urea groups was synthesised from a range of naturally-occurring materials including aliphatic diacids and triacids. These components were found to self-assemble, yielding a glassy plastic material $\left(T_{g}=28^{\circ} \mathrm{C}\right)$ which displayed elastomeric character when heated to temperatures above $90{ }^{\circ} \mathrm{C}$ (Figure 8). In order to obtain this character at room temperature, the hydrogen-bonded network required plasticisation with $11 \mathrm{wt} \%$ of dodecane.

\section{$<$ Figure 8 here $>$}

Analysis of the product by GPC and NMR confirmed the presence of a mixture of oligomers which, when plasticised, together behave as a self-repairable rubber. ${ }^{49}$ It was reported that once broken, the fracture interfaces were brought into contact at room temperature and within 5 minutes the self-healing process was complete. 
Rheological studies on the repaired rubber confirmed restoration of the original mechanical properties (Young's modulus of $10^{4} \mathrm{~Pa}$ ) (Figure 9).

\section{$<$ Figure 9 here $>$}

It is interesting to note that the broken network only retained its healable properties for a short period of time (ca. 5 minutes) after fracture. Beyond this time, the healing efficiency decreased and after an extended period it was not possible to repair the damaged material. It was proposed that the hydrogen-bonding groups which were initially capable of bridging the facture-surfaces reoriented over time to generate a new thermodynamically stable structure within each separate component of the fractured material. Thus, when the two broken sections were brought together during the healing procedure, new supramolecular bonds could not be formed within the fracture zone, and healing ceased to be possible. A similar time dependent healing phenomenon was observed by Aida et al. on healable supramolecular hydrogels, where it was found that recovery was only possible within 1 minute of the fracture occurring in the material. ${ }^{47}$

A series of novel, rehealable, non-covalent networks based on complementary aromatic $\pi$ - $\pi$-stacking interactions have recently been described by Colquhoun and Hayes et al. The first system of this type (Figure 10) comprised a low molecular weight polyimide 29 containing multiple $\pi$-electron deficient receptor sites (in blue). ${ }^{50}$ This polyimide proved capable of chain-folding ${ }^{51,52,53}$ around the $\pi$-electron rich pyrenyl chain ends (in red) of a telechelic polysiloxane $\mathbf{3 0}$ to form a complementary, $\pi-\pi$-stacked, non-covalent polymer complex. ${ }^{54}$ The healing behaviour of this polymer network was studied by environmental scanning electron microscopy (ESEM), which demonstrated rapid re-healing of the polymer network at temperatures greater than $90^{\circ} \mathrm{C}$.

\section{$<$ Figure 10 here $>$}

It was proposed ${ }^{50}$ that the healing process of this supramolecular network is initiated by partial dissociation of the complementary $\pi-\pi$-stacking interactions as the temperature rises. The dissociated components of the polymeric mixture can 
then flow to allow repair of the fracture site. On cooling, the non-covalent $\pi-\pi$ stacking interactions are progressively re-established, so regenerating the physical properties of the pristine material (Scheme 13).

\section{<Scheme 13 here $>$}

This preliminary study did indeed afford a repairable supramolecular network but the material proved to be rather brittle in nature. A second-generation healable supramolecular network was however developed ${ }^{55}$ which featured different polymer backbones - a double pyrenyl end-capped polyamide, $\mathbf{3 1}$, and a chainfolding co-polyimide 32 (Figure 11) - but which still exploited the same supramolecular $\pi$ - $\pi$-stacking motif described above. To demonstrate the importance of the supramolecular interaction within the network, a control polymer, 33 was synthesised. This polymer was designed to be identical to $\mathbf{3 1}$ in both the composition of the backbone and molecular weight, but differed in that it contained benzyl rather than pyrenyl endgroups.

\section{$<$ Figure 11 here $>$}

A visual demonstration of the healing characteristics of $[31+32]$ is given in Figure 12 (left hand column). A damaged film-sample (with a $75 \mu \mathrm{m}$ wide cut) was heated at $5{ }^{\circ} \mathrm{C} \mathrm{min}^{-1}$ in an environmental scanning electron microscope (ESEM). As the temperature reached ca. $80^{\circ} \mathrm{C}$ the material surrounding the cut was clearly seen to flow into the void and, at $90^{\circ} \mathrm{C}$ the film became essentially homogenous, with the position of the cut being scarcely visible. In contrast, ESEM analysis of a damaged film of the phase-separated material cast from a solution of $\mathbf{3 2}$ and $\mathbf{3 3}$ showed that the sample remained inhomogeneous up to $100^{\circ} \mathrm{C}$. Healing did not occur; indeed, the width of the break increased as the experiment progressed (Figure 12 right hand column).

\section{$<$ Figure 12 here>}

Rheometric investigations of this second-generation supramolecular polymer network [31+32] showed a tensile modulus of $\mathrm{ca} .1 \mathrm{MPa}$ at $30^{\circ} \mathrm{C}$. On breaking, it could be healed by simply pressing the broken ends gently in contact and heating 
briefly. Essentially quantitative recovery of tensile modulus was achieved almost instantly at $80^{\circ} \mathrm{C}$, or after ca. 5 minutes at $50^{\circ} \mathrm{C}$ (Figure 13a), a temperature at which the blend still has significant tensile modulus $\left(10^{4} \mathrm{~Pa}\right)$. Moreover, the blend of 31 and $\mathbf{3 2}$ (ca. 1:3 w/w, representing molar equivalence of diimide chain folds and pyrenyl end-groups) was found to fully regain the tensile modulus (ca. $1 \mathrm{MPa}$ ) of the pristine material over three cycles of breaking and healing. Unlike the healable supramolecular elastomer reported by Liebler et al., the blend material comprised of $\mathbf{3 1}$ and $\mathbf{3 2}$ could be fractured and the parts separated for at least 24 hours without any loss of healing efficiency (Figure 13b).

\section{$<$ Figure 13 here $>$}

\section{Conclusions}

Substantial progress has been made in recent years by research groups around the world in designing and synthesising polymers that are able to regain the physical properties of the pristine materials after physical damage. In all cases, a number of fundamental parameters must be considered: i) the stimulus (if any) and time required to heal the material, ii) the number of breaking and healing cycles which the material can sustain without loss of properties, and iii) the extent to which the material may be rehealed - taking account of all relevant physical parameters such as tensile modulus, elongation to break, fatigue-resistance, colour and transparency. In addition there is the practical requirement that, ultimately, the polymer system should be inexpensive and readily processable to enable it to move from being a purely research material to one with a significant impact on everyday life. With such a diverse range of parameters to be optimised it is clear that many formidable challenges remain, but that, as a consequence, tremendous potential exists for breakthroughs in the design and development of healable polymeric materials over the coming years.

\section{Acknowledgements}

We thank EPSRC for grants in support of our work in this field (EP/D07434711, EP/G026203/1 and DT/F007124/1).

\section{References}


1 K. Cousins, Polymers in Electronics, Smithers Rapra Technology Ltd, Shawbury, 2006.

2 M. Chanda and S. K. Roy, Plastics Technology Handbook, CRC, 1998.

3 Chem. Eng. News, 2003 (August 11 ${ }^{\text {th }}$ ) pp. 28-34.

4 Chem. Brit., 1999, (October) 35, 10, pp 24-26.

5 Z. W. Wicks, F. N. Jones, S. P. Pappas and D. A. Wicks, Organic Coatings, John Wiley \& Sons, Hoboken, New Jersey, 2007.

6 Chem. Eng. News, 2002 (February $4^{\text {th }}$ ) p. 29.

7 Chem. Ind-London, 2003 (October $6^{\text {th }}$ ) p. 19.

8 T. Osswald and G. Menges, Materials Science of Polymers for Engineers, Hanser Publishers, Munich, 2003.

9 S. D. Bergman and F. Wudl, J. Mater. Chem., 2008, 18, 41-62.

10 C. Dry and W. McMillan, Smart Mater. Struct., 1997, 6, 35-39.

11 D. Y. Wu, S. Meure and D. Solomon, Prog. Polym. Sci., 2008, 33, 479-522.

12 R. P. Wool, Soft Matter, 2008, 4, 400-418.

13 J. Wietor and R. P. Sijbesma, Angew. Chem. Int. Ed., 2008, 47, 8161-8163.

14 S. R. White, N. R. Sottos, P. H. Geubelle, J. S. Moore, M. R. Kessler, S. R.

Sriram, E. N. Brown and S. Viswanathan, Nature, 2001, 409, 794-797.

15 S. H. Cho, H. M. Anderson, S. R. White, N. R. Sottos and P. V. Braun, Adv. Mater., 2006, 18, 997-1000.

16 K. S. Toohey, N. R. Sottos, J. A. Lewis, J. S. Moore and R. S. White, Nature Materials, 2007, 6, 581-586.

17 J. W. C. Pang and I. P. Bond, Composites, Part A, 2005, 36, 183-188.

18 J. W. C. Pang and I. P. Bond, Compos. Sci. Technol., 2005, 65, 1791-1799.

19 A. Piermattei, S. Karthikeyan and R. P. Sijbesma, Nature Chemistry, 2009, 1, 133-137.

20 M. Stevens and A. Jenkins, J. Polym. Sci, 1979, 17, 3675-3685.

21 X. Chen, M. A. Dam, K. Ono, A. Mal, H. Shen, S. R. Nutt, K. Sheran and F. Wudl, Science, 2002, 295, 1698-1702.

${ }^{22}$ G. W. Goodall and W. Hayes, Chem. Soc. Rev., 2006, 35, 280-312.

${ }^{23}$ X. Chen, F. Wudl, A. K. Mal, H. Shen and S. R. Nutt, Macromolecules, 2003, 36, 1802-1807. 

1912. 3982-3984. 308, 1615-1617 2001, 101, 4071-4097. Rev., 2005, 105, 1491-1546. 373-380. California, 1988. 42, 8695-8702. Int. Pat. Appln. WO2008/063057,

Y. L. Liu and Y. W. Chen, Macromol. Chem. Phys., 2007, 208, 224-232.

Y. L. Liu, C. Y. Hsieh and Y. W. Chen, Polymer, 2006, 47, 2581-2586.

Y. Zhang, A. A. Broekhuis and F. Picchioni, Macromolecules, 2009, 42, 1906-

C. M. Chung, Y. S. Roh, S. Y. Cho and J. G. Kim, Chem. Mater, 2004, 16,

J. McMurry, Organic Chemistry, Brooks/Cole Publishing Company, Belmont,

T. F. Scott, A. D. Schneider, W. D. Cook and C. N. Bowman, Science, 2005,

B. Ghosh and M. W. Urban, Science, 2009, 323, 1458-1458.

P. J. De Gennes, J. Chem. Phys , 1971, 55, 572-579.

K. Jud, H. H. Kaush and J. G. Williams, J. Mater. Sci., 1981, 16, 204-210.

Y. H. Kim and R. P. Wool, Macromolecules, 1983, 16, 1115-1120.

Y. M. Boiko, G. Guérin, V. A. Marikhin and R. E. Prud'homme, Polymer, 2001,

L. Brunsveld, B. J. B. Folmer, R. P. Sijbesma and E. W. Meijer, Chem. Rev.,

A. Ciferri, Macromol. Rapid. Commun. 2002, 23, 511-529.

L. Perez-Garcia and D. B. Amabilino, Chem. Soc. Rev. 2007, 36, 941-967.

S. Sivakova and S. J. Rowan, Chem. Soc. Rev., 2005, 34, 9-21.

F. J. M. Hoeben, P. Jonkheijm, E. W. Meijer,A. P. H. J. Schenning, Chem.

G. F. Swiegers, T. J. Malefetse, Chem. Rev., 2000, 100, 3483-3537.

G. M. L. Hoorne-van-Gemert, H. M. Janssen, E. W. Meijer and A. W. Bosman,

S. Sivakova, D. A. Bohnsack, M. E. Mackay, P. Suwanmala and S. J. Rowan, J. Am. Chem. Soc., 1995, 127, 18202-18211.

F. R. Kersey, D. M. Loveless and S. L. Craig, J. R. Soc. Interface, 2007, 4,

S. J. Kalista Jr. and T. C. Ward, J. R. Soc. Interface, 2007, 4, 405 -411. 
46 S. J. Kalista Jr., T. C. Ward and Z. Oyetunji, Mech. Adv. Mater. Struct., 2007, 14, 391-397.

47 Q. Wang, J. L. Mynar, M. Yoshida, E. Lee, K. Okuro, K. Kinbara and T. Aida, Nature, 2010, 463, 339-343.

48 P. Cordier, F. Tournilhac, C. Soulie'-Ziakovic and L. Leibler, Nature, 2008, 451, 977-980.

49 D. Montarnal, P. Cordier, C. Soulié-Ziakovic, F. Tournilhac and L. Leibler J. Polym. Sci. Part A: Polym .Chem, 2008, 46, 7925-7936.

50 S. Burattini, H. M. Colquhoun, B. W. Greenland and W. Hayes, Faraday Discuss., 2009, 143, 251-264.

51 R. S. Lokey and B. L. Iverson, Nature, 1995, 375, 303-305.

52 R. S. Lokey, Y. Kwok, V. Guelev, C. J. Pursell, L. H. Hurley and B. L. Iverson, J. Am. Chem. Soc. 1997, 119, 7202-7210.

53 J. Q. Nguyen and B. L. Iverson, J. Am. Chem. Soc., 1999, 121, 2639-2640.

54 B. W. Greenland, S. Burattini, W. Hayes and H. M. Colquhoun, Tetrahedron, 2008, 64, 8346-8354.

S. Burattini, H. M. Colquhoun, J. D. Fox, D. Friedmann, B. W. Greenland, P. J. F. Harris, W. Hayes, M. E. Mackay and S. J. Rowan, Chem. Commun., 2009, 44, 6717-6719. 